Food and Agriculture Organization of the United Nations (1949). Dietary Surveys. Their Technique and Interpretation. Washington: Food and Agriculture Organization of the United Nations.

McHenry, E. W., Ferguson, H. P. \& Gurland, J. (1945). Canad. publ. Hlth F. 36, 355.

McKay, J. \& Patton, M. B. (1935). Bull. Ohio agric. Exp. Sta. no. 549.

National Research Council (1948). Repr. nat. Res. Coun., Wash., no. I29.

Platt, B. S. (1945). Spec. Rep. Ser. med. Res. Coun., Lond., no. 253.

Wait, B. \& Roberts, L. J. (1932). Y. Amer. diet. Ass. 8, 323.

Widdowson, E. M. (1947). Spec. Rep. Ser. med. Res. Coun., Lond., no. 257.

Widdowson, E. M. \& McCance, R. A. (1943). Lancet, 244, 230.

Widdowson, E. M. \& McCance, R. A. (1945). Proc. Nutr. Soc. 3, i ro.

Yudkin, J. (1948). Nutrit. Diet. Catering, 2, 43.

\title{
The Evaluation of Leanness-Fatness in Man: Norms and Interrelationships
}

\author{
BY J. BROŽEK AND A. KEYS \\ Laboratory of Physiological Hygiene, University of Minnesota, \\ Minneapolis, U.S.A. \\ (Received 3 October 1950)
}

One of the fundamental characteristics of man's state of nutrition is the composition of his body. Grossly, at least, this means the proportion of his body-weight accounted for by the basic components of blood (subdivided into plasma and cells), interstitial fluid, bone, fat, and 'active tissues' (principally muscles, glands, and nerves). Body fat shows the most striking variations in states of nutrition varying along the emaciation-obesity continuum. The provision of improved methods for a quantitative estimation of the relative fatness is one of the pressing tasks of nutritional science; it is essential both for the evaluation of calorie nutrition and for the establishment of valid estimates of calorie requirements (cf. Food and Agriculture Organization of the United Nations, 1950).

In the past, the evaluation of fatness has been based almost exclusively on the individual's deviation from some 'standard' reference weight for his sex, age and height. This conforms to popular ideas; a 'fat' person is thought of as a heavy, overweight individual. Clinical monographs on obesity (Rony, r940; Rynearson \& Gastineau, r949) devote little or no space to a quantitative evaluation of the degree of obesity. This is defensible if one is concerned only with very marked deviations from normal where, in the absence of oedema, a large increase in weight is likely to mean simply the accumulation of body fat. Experience with animals generally supports the concept of overweight as 'fatness'. A very heavy pig or goose will not only have a larger total weight than a lean animal of the same breed but, at the same time, a disproportionately large percentage of their body-weight will be accounted for in terms of deposited fat.

In man, variations in physical activity may alter markedly the composition of the body and disturb the relationship between the relative body-weight and fatness so that the relative body-weight (obtained by expressing the actual weight as a percentage 
of 'standard' weight) for height, sex and age may be grossly misleading as an index of fatness. Welham \& Behnke (r942), in their study of professional football players, demonstrated that 'overweight' cannot be simply identified with 'obesity'. The football players were actually 'thin', in the sense of having a low fat content of the body, although the average body-weight was $24.6 \%$ above the army standard for men of the same height and age.

On the lower ('lean') end of the scale, the relationship between relative body-weight (underweight) and leanness may be more stable. In all field reports from areas where there was undernutrition and semi-starvation, including observations made during and after the second world war, marked decrements in body fat have been noted. Unfortunately, almost all of these reports present only qualitative descriptions of the semi-starvation changes. If quantitative data are presented, they are limited to body-weight.

In the Minnesota starvation-rehabilitation experiment (Keys, Brožek, Henschel, Mickelsen \& Taylor, 1950) the weight decreased within 6 months from 69.39 to $52.57 \mathrm{~kg}$. (a decrement of $24.2 \%$ of the original value), while the body fat, estimated on the basis of specific gravity, decreased from 9.84 to $3.05 \mathrm{~kg}$. (a change of $69.0 \%$ ) (Brožek, 1946). In the rehabilitation period the recovery of the body fat was more rapid than the recovery of the other soft tissues. In the caloric groups, maintained on supplements differing by successive steps of about $400 \mathrm{Cal}$., the total body-weight was regained to the extent of $21,30,4 \mathrm{I}$ and $56 \%$ of the semi-starvation loss, whereas for body fat the recovery of $17 \cdot 0,42.5,45.9$ and $94.8 \%$ was achieved in this same period.

The method of estimating body fat from specific gravity of the body offers an important advance in the quantitative macroscopic morphology of the living man, even though much yet remains to be done in the way of further validation, refinement, and simplification of the technique. Measurements of the skinfolds, which vary in thickness roughly in proportion to the subcutaneous adipose tissue, are being used with increasing frequency as criteria of fatness, but there are as yet no adequate standardized procedures and instruments. Without such standardization the establishment of usable norms for well-defined sectors of the population will be impossible.

A general review of methods for the evaluation of fatness-leanness (obesity-emaciation) of an individual has been published elsewhere (Brožek \& Keys, 1950a). The present communication offers specific data obtained for two age groups, younger men (college age) and older men ( $45-55$ years). The study is focused on the problem of the norms and the interrelationships between different measures of fatness.

\section{Criteria of leanness-fatness}

\section{METHODS}

The characterization of man's 'leanness-fatness' in this paper is based on the measurement of (I) specific gravity of the body, (2) thickness of skinfolds, and (3) external dimensions and body-weight. In living man the percentage of the body represented by fat, estimated on the basis of specific gravity of the body, appears to be the best single criterion for characterizing the individual's leanness-fatness. The 
skinfolds may be regarded as the next best index. 'Impure' characteristics, such as the abdominal circumference and the gross body-weight, provide still more indirect indicators of the leanness-fatness of an individual.

Specific gravity of the body. The possibility of estimating the amount of body fat from the specific gravity of the body was demonstrated by Behnke and his collaborators (Behnke, 1941-2; Behnke, Feen \& Welham, 1942). This technique takes into account both the subcutaneous fat and the deeper fat deposits. This is of importance because the tela subcutanea accounts for much, but not all, of the adipose tissue. A table for converting the values of specific gravity of man to fat content was provided by Rathbun $\&$ Pace (1945).

In the present study the body volume, used in the calculation of body density, was obtained on the basis of the Archimedean principle: volume (1.)=weight in air $(\mathrm{kg}$.$) - weight in water (kg.). The subjects were seated in a stainless steel support and$ lowered into a tank of water $\left(3^{6} \pm 0.5^{\circ}\right)$. They exhaled maximally through a copper tube and held their breath for $3-5 \mathrm{sec}$. needed for reading the weight to the nearest roo $\mathrm{g}$. The procedure and equipment have been described elsewhere (Brožek, Henschel \& Keys, 1949).

The value of the under-water weight has to be corrected for the air remaining in the lungs and repiratory passages at the end of maximal expiration. On the basis of the available data the correction factor of 1.51 . appears as an acceptable approximation of the average value of residual air volume for young men; in individual cases the correction involves an error which rarely exceeds $\pm 600 \mathrm{ml}$. The volume of residual air increases, on the average, with age. For the older men, the value of $2 \cdot 21$. was used (Brožek, Carlson \& Keys, 195I).

Thickness of skinfolds. The skinfolds were picked up between the thumb and the index finger of the left hand and lifted up, taking care that no underlying muscle tissue was included. The 'bite' covered about $8 \mathrm{~cm}$. of the skin. In very obese individuals the distance had to be increased. The thickness, which represents twice the value of the thickness of the skin plus the subcutaneous tissues, was determined by a pair of calipers. The calipers were placed about $1 \mathrm{~cm}$. above the fingers, holding the skinfold lightly and allowing the pressure of the calipers alone to be applied to the skinfold.

It is obvious that the values are dependent, in part, on the characteristics of the instrument used. The area of the contact points of the calipers was about $3 \mathrm{sq} . \mathrm{mm}$. and the initial (opening) tension was $110 \mathrm{~g} .(35.4 \mathrm{~g} . / \mathrm{sq} . \mathrm{mm}$.). There was only a small increase in the pressure when the jaws of the calipers were opened more widely. Over the range of skinfold thicknesses encountered in this study the effective tension increased linearly $(7 \cdot 8 \mathrm{~g} . / \mathrm{cm}$. jaw opening). This variation did not affect appreciably the skinfold values as shown by studies with special calipers on a group of twelve young men. The skinfolds were measured at five points: ( 1 ) abdomen, to the right of the navel, (2) chest, above and to the right of the right nipple, (3) back, below the right scapula, (4) arm, on the back, half-way down the upper arm, (5) thigh, above the knee cap.

Relative body-veight. In evaluating the degree of 'overweight', the subject's actual 
body-weight was expressed as a percentage of the standard reference weight for the man's age and height. The ages were calculated in terms of the nearest birthday. The weight was measured to the nearest $100 \mathrm{~g}$. The weights in Table IV of the Medicoactuarial Mortality Investigation, abbreviated as M.A.I. (Association of Life Insurance Medical Directors and the Actuarial Society of America, 1912, p. 38) served as standards of reference. This table has been reprinted by Davenport (1923) and cited in numerous other publications, frequently without reference to the original source (see, for example, McLester, 1943, p. 771).

'The M.A.I. data have no magic properties and are by no means to be considered as 'ideal' weights, a quality which can be established only on the basis of thorough morbidity and mortality studies, but for 40 years they seem to have been reasonably good average values for 'normal', i.e. non-diseased, Americans. The figures derived from a sample of 100,000 white registrants for the draft, measured in $194^{\circ}$ and $194 \mathrm{I}$, with an average age of 26 years (Edwards, McGill \& Rowntree, 1943) agreed closely with the M.A.I. reference weights for men 26 years old.

Body dimensions. The chest and the abdominal circumference were measured with a steel tape at the end of normal expiration. For some purposes the absolute values of these dimensions or their ratios to height are of interest. In the present study the difference between the thoracic and abdominal circumference was used. Behnke $e t$ al. (1942) and Sarkisian (1946) pointed out that this difference tends to parallel the specific gravity and can serve as a gross measure of fatness-leanness.

\section{Subjects and conditions}

In selecting the subjects several criteria were applied: (I) health, the subjects were to be free of discoverable disease; (2) sex, only men were included; (3) age, the sample consisted of two age groups: younger adults (college age) and older adults (ages 45-55 years); (4) occupation, the younger men were students at the University of Minnesota, the older men were business and professional men in Minneapolis and St Paul; (5) relative weight, a fairly wide range was desired.

For the purposes of examining the relationship between fatness and the cardiovascular functions a larger number of overweight individuals was included in the sample than would be likely to be found in a random sample of the population. In the student group this resulted in a distribution of relative body-weights that was slightly skewed toward the higher values. The mean weight of the original group of 159 normal students was $73.3 \mathrm{~kg}$., or $106 \%$ of the 'standard' weight (69. $\mathrm{kg}$.) for age $(20.4$ years) and height $(177.8 \mathrm{~cm}$.).

In selecting the older group for the cardiovascular study, effort was made to obtain a rectangular distribution, with approximately equal numbers of subjects in the five categories according to the relative body-weight (group $A=$ below $85.0 \%$ of the standard age-height-weight; $\mathrm{B}=85^{\circ} \cdot 0-94^{\circ} 9 ; \mathrm{C}=95^{\circ} \circ-104.9 ; \mathrm{D}=105^{\circ} 0-114^{\circ}$; $\mathrm{E}=115.0 \%$ and above). To this sample was added a group of men certified as 'physically active' by the directors of local athletic clubs. For the 223 physically normal older men (average age 49.2 years) the actual mean weight $(74.9 \mathrm{~kg}$.) was close 
to the 'standard' weight $(75.9 \mathrm{~kg}$.) for height $(175.9 \mathrm{~cm}$.$) , but the distribution was$ not representative of any definable population.

For the purpose of arriving at norms of fatness-leanness we have selected from each of our two groups a subsample which followed closely, with reference to the relative body-weight, the distribution of this characteristic in a random sample of a welldefined population. 'Through the courtesy of Dr Ruth Boynton, director of the Student Health Service, University of Minnesota, we were able to obtain the distribution of relative weights in two random samples of students (age $r 8-26$ years) registering at the

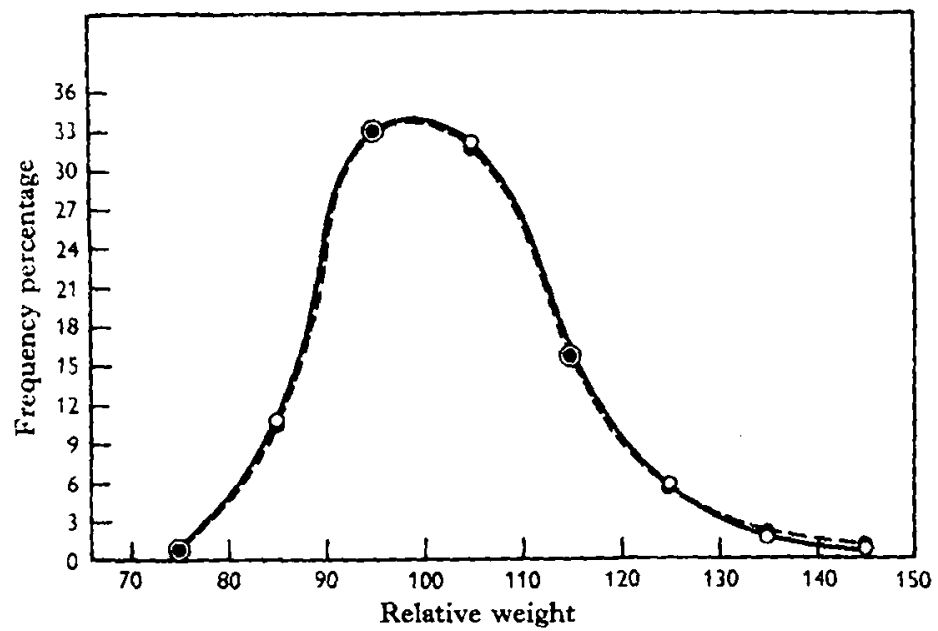

Fig. I. Distribution of the relative weights in a random sample of University of Minnesota students $(N=7116$, solid circles) and in a matched sample $(N=133$, open circles $)$ used for establishing the norms of the fatness criteria.

University. The distributions obtained for 2 successive years were almost identical. We have used the combined sample $(N=7116)$ and selected out of our population of young subjects a subsample that matched the distribution of relative weights in the student population. Within the intervals of relative weight the subjects were selected at random.

For the older men no data on the distribution of relative weight in a random sample of business and professional men, free of disease, could be found in the literature. In order to approximate a random sample we have combined the data for all of the 566 business and professional men with whom we have had contact and who were judged to be free from disease. In making up the subsample for the derivation of norms of fatness for this age group the subjects were selected so as to match the distribution of relative weights found in this sample of $566 \mathrm{men}$.

The model and the matched distributions for the younger and older subjects are given in Figs. $\mathrm{I}$ and 2.

\section{Norms}

\section{RESULTS}

The norms were derived from the frequency distributions of the single criteria of fatness. When the distributions are 'normal', in the statistical sense, the norms can be based effectively on the mean and the standard deviation of the values in the sample. When this is not the case the norms may be based on percentiles. 
For the purposes of classification of the subjects into categories of fatness, we have used the twentieth, fortieth, sixtieth and eightieth percentile. These limit values are sometimes called 'quintiles'. They divide the sample into five equal groups, as far as the number of individuals in each fatness category is concerned. The quintiles, together with the fiftieth percentile (the median) are given in Tables I and 2. For completeness, the means and standard deviations are also indicated. It may be noted that some of the distributions of fatness measures for the younger men showed considerable skewness.

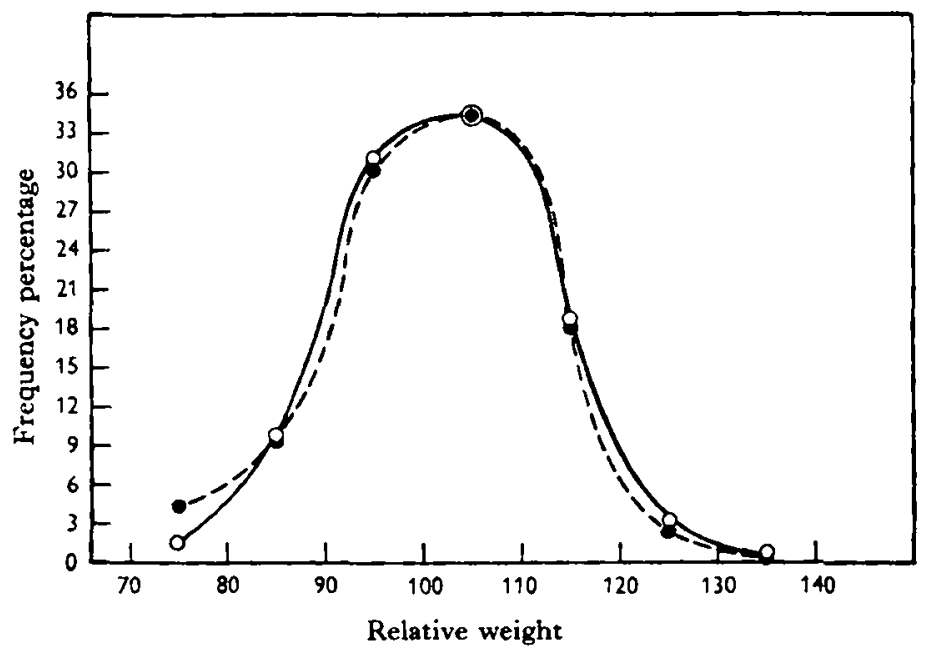

Fig. 2. Distribution of the relative weights in a group of older men (45-55 years of age, $N=566$, solid circles) who volunteered as subjects for the cardiovascular study and in a matched sample $(N=122$, open circles) used for establishing the fatness criteria.

Table I. Normative data on indices of leanness-fatness for male college students

\begin{tabular}{|c|c|c|c|c|c|c|c|}
\hline \multicolumn{8}{|c|}{$(N=133 ;$ mean age $=20.3$ years, s.D. $=1.9)$} \\
\hline \multirow[b]{2}{*}{ Criterion } & \multicolumn{4}{|c|}{ Percentiles } & \multirow[b]{2}{*}{$\begin{array}{c}\text { Median } \\
5^{\circ}\end{array}$} & \multirow[b]{2}{*}{ Mean } & \multirow[b]{2}{*}{ S.D. } \\
\hline & 20 & 40 & 60 & 80 & & & \\
\hline $\begin{array}{l}\text { Relative body-weight } \\
\text { Specific gravity } \\
\text { Percentage of body fat }\end{array}$ & $\begin{array}{r}91 \cdot 6 \\
I \cdot 0893 \\
4 \cdot 92\end{array}$ & $\begin{array}{r}97.0 \\
I \cdot 0820 \\
8.40\end{array}$ & $\begin{array}{l}102 \cdot 7 \\
1 \cdot 0746 \\
I 1 \cdot 90\end{array}$ & $\begin{array}{l}113 \cdot 6 \\
1 \cdot 0645 \\
16 \cdot 77\end{array}$ & $\begin{array}{c}99 \cdot 7 \\
I \cdot 0781 \\
10.25\end{array}$ & $\begin{array}{r}I 0 I \cdot 4 I \\
I \cdot 0766 \\
10.93\end{array}$ & $\begin{array}{r}11 \cdot 94 \\
0.0141 \\
-\end{array}$ \\
\hline \multicolumn{8}{|l|}{ Skinfolds (mm.): } \\
\hline Abdomen & $1 I \cdot I$ & $14 \cdot 5$ & $19 \cdot 1$ & $24 \cdot 8$ & $16 \cdot 2$ & $18 \cdot 2$ & $8 \cdot 4$ \\
\hline Chest & 9.5 & $12 \cdot 3$ & $16 \cdot 1$ & $22 \cdot 5$ & 14.2 & I $5^{\bullet} 9$ & $7 \cdot 4$ \\
\hline Back & $9 \cdot 4$ & $11 \cdot 8$ & $14 \cdot 8$ & $19 \cdot 0$ & $13 \cdot 3$ & $14: 3$ & $5 \cdot 8$ \\
\hline Arm & $6 \cdot 6$ & $9 \cdot 1$ & $11 \cdot 6$ & $14 \cdot 6$ & $10 \cdot 2$ & $10 \cdot 9$ & $4 \cdot 6$ \\
\hline Thigh & $5 \cdot 6$ & $7 \cdot 6$ & $9 \cdot 1$ & II 0 & $8 \cdot 5$ & $8 \cdot 6$ & $3 \cdot 7$ \\
\hline $\begin{array}{l}\text { Chest circumference - } \\
\text { abdominal circumfer }\end{array}$ & $17 \cdot 1$ & 15.0 & $12 \cdot 2$ & 9.4 & 13.4 & $13^{\circ} 2$ & $5 \cdot 1$ \\
\hline
\end{tabular}

(cm.)

We have available three other distributions of specific gravity with incomplete information on the distribution of relative weight and age. These data were obtained for ninety-nine Navy men between 20 and 40 years of age (Behnke et al. 1942), for a similar sample of seventy-five Navy men (Welham \& Behnke, 1942), and for thirty-two 
Table 2. Normative data on indices of leanness-fatness for middle-aged men

\begin{tabular}{|c|c|c|c|c|c|c|c|}
\hline & $(N=$ & ; mean & $=49^{\circ} \circ$ & rs, S.D. & & & \\
\hline & & Perc & tiles & & & & \\
\hline Criterion & 20 & 40 & 60 & 80 & 50 & Mean & S.D. \\
\hline $\begin{array}{l}\text { Relative body-weight } \\
\text { Specific gravity } \\
\text { Percentage of body fat }\end{array}$ & $\begin{array}{l}92 \cdot 4 \\
x \cdot 0656 \\
16 \cdot 3\end{array}$ & $\begin{array}{l}98 \cdot 7 \\
I \cdot 0590 \\
19 \cdot 5\end{array}$ & $\begin{array}{l}104 \cdot 6 \\
1 \cdot 0523 \\
22 \cdot 7\end{array}$ & $\begin{array}{l}111 \cdot 6 \\
1 \cdot 0460 \\
26 \cdot 0\end{array}$ & $\begin{array}{l}101 \cdot 5 \\
1 \cdot 0560 \\
21 \cdot 0\end{array}$ & $\begin{array}{l}101 \cdot 8 \\
1 \cdot 0554 \\
21 \cdot 3\end{array}$ & $\begin{array}{c}11 \cdot 31 \\
0.01182 \\
-\end{array}$ \\
\hline Skinfolds (mm.): & & & & & & & \\
\hline Abdomen & $18 \cdot 6$ & $23 \cdot 1$ & $26 \cdot 9$ & $3 r \cdot 5$ & $25^{\circ} 0$ & $25 \cdot 5$ & $7 \cdot 8$ \\
\hline Chest & $18 \cdot 4$ & $23 \cdot 1$ & $26 \cdot 4$ & $3 \mathbf{1} \cdot 3$ & 24.7 & $24 \cdot 5$ & $7 \cdot 8$ \\
\hline Back & $14 \cdot 2$ & $17 \cdot 7$ & $20 \cdot 8$ & $24 \cdot 5$ & $19 \cdot 3$ & 19.9 & $7 \cdot 1$ \\
\hline Arm & 10.9 & 13.4 & 14.9 & $18 \cdot 2$ & $x \cdot 1$ & 14.4 & 4.2 \\
\hline Thigh & 8.0 & 9.6 & 10.9 & $12 \cdot 7$ & $10 \cdot 1$ & 10.3 & $3^{\circ} 0$ \\
\hline $\begin{array}{l}\text { Chest circumference - } \\
\text { abdominal circumference } \\
(\mathrm{cm} .)\end{array}$ & $e^{114}$ & 8.0 & $5 \cdot 7$ & $4 \cdot 1$ & 6.8 & $7 \cdot 2$ & $4^{.6}$ \\
\hline
\end{tabular}

Table 3. Distribution of specific gravity in 206 healthy young men, 20-40 years of age

$\begin{array}{ccccccr}\text { Specific gravity } & \begin{array}{c}\text { Navy } \\ \text { men } \\ (99)\end{array} & \begin{array}{c}\text { Navy } \\ \text { men } \\ (75)\end{array} & \begin{array}{c}\text { Conscientious } \\ \text { objectors } \\ (\mathbf{3 2})\end{array} & \begin{array}{c}\text { Total } \\ f\end{array} & f \% & \Sigma f \% \\ 1 \cdot 020-1 \cdot 029 & 2 & - & - & 2 & 0.97 & 100 \cdot 00 \\ 1 \cdot 030-1 \cdot 039 & 2 & 1 & - & 3 & 1 \cdot 46 & 99 \cdot 03 \\ 1 \cdot 040-1 \cdot 049 & 4 & 1 & 1 & 6 & 2 \cdot 91 & 97.57 \\ 1 \cdot 050-1 \cdot 059 & 20 & 11 & 5 & 36 & 17.48 & 94.66 \\ 1 \cdot 060-1 \cdot 069 & 23 & 18 & 7 & 48 & 23.30 & 77 \cdot 18 \\ 1 \cdot 070-1 \cdot 079 & 27 & 14 & 12 & 53 & 25.73 & 53.88 \\ 1 \cdot 080-1 \cdot 089 & 14 & 16 & 7 & 37 & 17 \cdot 96 & 28 \cdot 15 \\ 1 \cdot 090-1 \cdot 099 & 7 & 14 & - & 21 & 10.19 & 10 \cdot 19\end{array}$

conscientious objectors (Keys et al. 1950), 20-33 years of age, mean age 25.5 . The data are summarized in Table 3.

The mean is $\mathrm{r} .07 \mathrm{II}$ (corresponding to $13.6 \%$ of the body as fat), the median 1.0714 , the standard deviation 0.0145 . The twentieth, fortieth, sixtieth and eightieth percentiles are $1 \cdot 0845,1 \cdot 0753,1 \cdot 0653$ and $1 \cdot 0583$. These figures fall between those for the college and the business and professional groups. They were obtained on healthy young men and may perhaps be regarded as an approximation to 'ideal' values of fatness in the adult man. An increase in fatness with age appears undesirable even though, statistically, a continuing rise in the relative amount of body fat is a 'normal' phenomenon.

\section{Estimation of the total fatness-leanness from single variables}

One of the aims of this study was to develop equations for estimating the total fatness from more easily accessible measures of fatness than the specific gravity. The prediction equations are based on the means, standard deviations and the coefficients of correlation, but for application to calculations we have converted these to the simple form, $\vec{Y}=a+b X$. These prediction equations for the several indirect fatness criteria are presented in Table 4. 
Table 4. Equations for prediction of specific gravity of the body $(Y=a+b X)$ on the basis of single fatness criteria

(The skinfold values are in $\mathrm{mm}$.)

$\quad$ Variable
Skinfolds:
Abdomen
Chest
Back
Upper arm
Thigh
Relative body-weight

$\overbrace{\text { Younger men }}^{\text {Group }}$

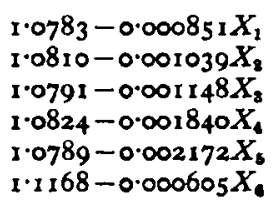

The coefficients of correlation between specific gravity and other criteria of fatnessleanness are presented in Table 5. The effectiveness of estimating $Y$ from $X$ does not increase linearly with increasing values of $r$. For this reason it is preferable in interpreting the meaning of a correlation coefficient to express the 'goodness of prediction' in terms of the index of forecasting efficiency $(F . E .)^{*}$. This index gives directly the percentage of reduction in the error of prediction for a given $r$. These data are also given in Table 5 .

Table 5. Coefficients of correlation ( $r$ between specific gravity and other criteria of fatness-leanness for younger $(N=116)$ and older $(N=214)$ men, indices of forecasting efficiency (F.E.), and standard errors of estimate of the specific gravity (S.E.E.)

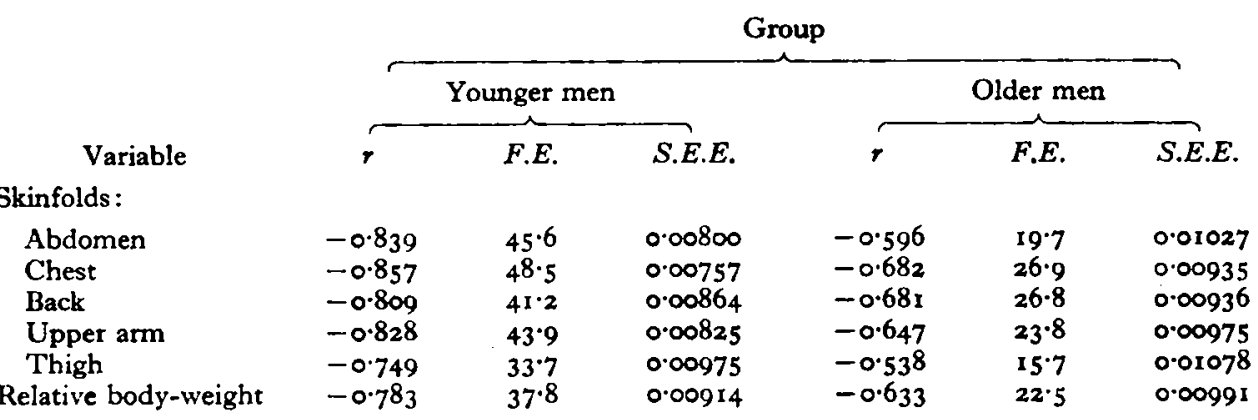

The coefficients of correlation are lowered (attenuated) by the 'errors of measurement'. In addition to the effect of variation in the readings present in all types of measurement, the values of specific gravity are subject to the error arising from the fact that the volumes of residual air were not determined for every individual, but an average value was used.

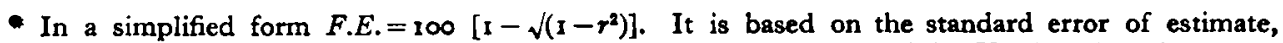
S.E.E. = S.D. $Y \sqrt{ }\left(1-r^{2}\right)$, expressed as percentage of the standard deviation of the $Y$ values (S.D. $r$ ):

$$
\text { F.E. }=100-100 \frac{\text { S.D. } Y \sqrt{ }\left(1-r^{2}\right)}{\text { S.D.Y }} .
$$




\section{Total fatness-leanness estimated from combined variables}

The accuracy of prediction may be raised by combining several prediction variables. The simplest, but not the most effective, approach is to consider all estimates as having the same validity (i.e. assign to each of them a 'weight' of $\mathrm{I}$ ) and average the several estimates obtained. The technique of simple averaging does not allow a precise evaluation of the reduction in the error of estimate resulting from pooling several prediction variables. This may be achieved by predicting the specific gravity on the basis of a multiple regression equation. This technique takes into account both the correlations of each variable with the criterion (i.e. the specific gravity) and the intercorrelations between the variables. In combining the measurements, economy of effort calls for variables that have a high correlation with the criterion but low correlation with the other prediction variables. The basic correlation coefficients are presented in Tables 6 and 7.

Table 6. Intercorrelations between indices of fatness for younger men $(N=116 ; \text { mean age }=21 \cdot 9 \text { years, S.D. }=2 \cdot 0)^{*}$

$\begin{array}{lccccccc} & (Y) & \left(X_{1}\right) & \left(X_{2}\right) & \left(X_{3}\right) & \left(X_{1}\right) & \left(X_{5}\right) & \left(X_{6}\right) \\ \text { Specific gravity } & - & -0.839 & -0.857 & -0.809 & -0.828 & -0.749 & -0.783 \\ \text { Skinfolds: } & & & & & & & \\ \quad \text { Abdomen } & -0.839 & - & +0.938 & +0.900 & +0.853 & +0.752 & +0.804 \\ \text { Chest } & -0.857 & +0.938 & - & +0.914 & +0.858 & +0.766 & +0.832 \\ \text { Back } & -0.809 & +0.900 & +0.914 & - & +0.827 & +0.768 & +0.864 \\ \text { Arm } & -0.828 & +0.853 & +0.858 & +0.827 & - & +0.803 & +0.780 \\ \text { Thigh } & -0.749 & +0.752 & +0.766 & +0.768 & +0.803 & - & +0.776 \\ \text { Relative body-weight } & -0.783 & +0.804 & +0.832 & +0.864 & +0.780 & +0.776 & -\end{array}$

- The correlations were computed from measurements obtained during the and year of the study.

Table 7. Intercorrelations between indices of fatness for older men $(N=214 ;$ mean age $=49 \cdot 2$ years, S.D. $=2 \cdot 8) *$

$\begin{array}{lccccccc} & (Y) & \left(X_{1}\right) & \left(X_{2}\right) & \left(X_{3}\right) & \left(X_{1}\right) & \left(X_{5}\right) & \left(X_{0}\right) \\ \text { Specific gravity } & - & -0.596 & -0.682 & -0.681 & -0.647 & -0.538 & -0.633 \\ \text { Skinfolds: } & & & & & & & \\ \text { Abdomen } & -0.596 & - & +0.794 & +0.758 & +0.633 & +0.550 & +0.693 \\ \text { Chest } & -0.682 & +0.794 & - & +0.799 & +0.717 & +0.542 & +0.692 \\ \text { Back } & -0.681 & +0.758 & +0.799 & - & +0.730 & +0.602 & +0.752 \\ \text { Arm } & -0.647 & +0.633 & +0.717 & +0.730 & - & +0.692 & +0.644 \\ \text { Thigh } & -0.538 & +0.550 & +0.542 & +0.602 & +0.692 & - & +0.634 \\ \text { Relative body-weight } & -0.633 & +0.693 & +0.692 & +0.752 & +0.644 & +0.634 & -\end{array}$

- The correlations were computed from measurements made on all older men for whom specific gravity values were available and who were clinically normal.

The values needed for the multiple prediction equation were obtained by the Doolittle method (Johnson, 1949, p. 327). The general formula of the equation is

$$
\hat{Y}=a+b_{1} X_{1}+b_{2} X_{2}+\ldots+b_{n} X_{n},
$$

where the $b$ values are 'weights' yielding the best estimate of the predicted variable, $\hat{Y}$, obtained by a linearly additive combination of the prediction variables. Technically, 
the $b$ values are referred to as partial regression coefficients. The value $a$ is a constant, defined as

$$
a=\bar{Y}-\left(b_{1} \bar{X}_{1}+b_{2} \bar{X}_{2}+\ldots+b_{n} \bar{X}_{n}\right) .
$$

Using six variables, we obtain the following equations for predicting the specific gravity of the younger and older men, respectively (equations $I$ and 2):

$$
\begin{aligned}
\hat{Y}= & \mathrm{r} \times 125-0.000292 X_{1}-0.00066 \mathrm{r} X_{2}+0.00018 \mathrm{I} X_{3} \\
& -0.0007 \mathrm{I} X_{4}-0.000375 X_{5}-0.000122 X_{6}, \\
\hat{Y}= & \mathrm{r} .0967+0.000042 X_{1}-0.000423 X_{2}-0.000320 X_{3} \\
& -0.00051 \mathrm{I} X_{4}-0.000247 X_{5}-0.000156 X_{6} .
\end{aligned}
$$

The coefficients of multiple correlation between specific gravity and the six prediction variables are $R_{Y \cdot 128458}=0.8760$ for younger, and $R_{Y} \cdot 123456=0.744 \mathrm{I}$ for the older men. This corresponds to the standard errors of the specific gravity estimates of 0.00708 and 0.00854 , and indices of prediction efficiency of 51.8 and $33.2 \%$.

In order to reduce the labour involved in making the actual measurements and in predicting the specific gravity, those variables that did not contribute significantly to the accuracy of prediction were removed. Johnson (1949, p. 339) presents in detail the steps involved in testing the statistical significance of the partial regression coefficients and in calculating the simplified prediction equations. On this basis, the following prediction equations were derived for the younger and older men (equations 3 and 4$)$, respectively:

$$
\begin{gathered}
\hat{Y}=1 \cdot 1017-0.000282 X_{1}-0.000736 X_{2}-0.00088_{3} X_{4}, \\
\hat{Y}=1 \cdot 0967-0.000393 X_{2}-0.000315 X_{3}-0.000598 X_{4}-0.000170 X_{8} .
\end{gathered}
$$

The accuracy of predicting specific gravity of the younger men from equation (3) is characterized by $R=0.8709$, standard error of estimate $=0.00722$, and $F . E .=50.9 \%$. For the older men (equation 4 ), $R=0.7430$, standard error of estimate $=0.00856$, and $F . E .=33 \cdot 1 \%$.

\section{Discussion}

\section{Implications of the data for nutritional research}

Quantitative morphology of the body mass, separated into its primary components, provides the initial framework for the description of man's nutritional status. In living man, partitioning of the body into the principal tissues, including body fat, must be carried out largely by indirect methods.

For classifying individuals several criteria may be used: body-weight related to the 'standard' weight for age, sex and height; external body dimensions, either singly or, preferably, in combinations such as the difference between the circumference of the chest and the abdomen; skinfolds; specific gravity. Norms were provided here for classification of normal men of college age and of business and professional men in the age bracket of 45-55 years, using eight criteria of fatness. These data should provide useful reference material for other investigators. Extension of the work to other age levels and to women is much needed. 
'The validities of these criteria differ. Final validity can be established directly only on the basis of correlating the values of the particular criterion with subsequent analyses of the actual fat content of the body. Technically, any attempt at such a validation would meet almost insuperable obstacles. Quantitative analyses of cadavers are conspicuous by their rarity (see Mitchell, Hamilton, Steggerda \& Bean, 1945).

In the present study the validation of the more indirect or partial indicators of fatness was carried out in terms of correlations with the specific gravity. The chest skinfolds showed the highest correlation with specific gravity in both age groups ( $r=-0.857$ for the younger men, $r=-0.682$ for the older men). The relative weight showed a surprisingly high correlation $(-0.783$ and -0.633 , respectively). However, it should be noted that this relationship holds only within a limited age range. We have pointed out (Brožek \& Keys, 1950 $b$ ) that older men have a higher fat content at the same relative weight. In a group of thirty-seven younger men (mean age 22. I years) and sixty-six older men (mean age $44 \cdot 1$ years) who were within $\pm 5 \%$ of their standard weight (mean relative weight of $100 \cdot 2$ and $100 \cdot 0$ ) the values for mean body fat, estimated from specific gravity corrected for residual air in the lungs, were $9 \cdot 8$ and $2 \mathrm{r} \cdot 0 \%$.

At times, information on the absolute amount of body fat is desirable. For example, one may wish to refer the basal metabolic rate not to the gross body-weight (or to body surface, estimated from body-weight and height), but to the fat-free body mass. In the present paper, equations were provided for estimating total fat from the less direct criteria of fatness, both singly and combined into a multi-variable prediction equation. The estimation equations were developed for the specific gravity rather than for the total storage fat. In a way it would be easier to think directly in terms of the estimated body fat rather than the specific gravity; for one, the correlations with the majority of the indices of body fat would be positive. However, it may turn out in the course of further research that the conversion tables worked out by Rathbun \& Pace (1945) will need revision. Such a revision would not affect the prediction equations developed in this paper.

\section{Skinfolds, selection of points}

In the present study the points at which the skinfolds were to be measured were selected on a priori grounds. The following conditions were to be satisfied: (I) representation of regions known to show large variations in subcutaneous fat (abdomen, chest), (2) representation of the extremities (arm and thigh measurements) and (3) ease of precise location.

The information provided here throws much-needed light on the value of different skinfolds as predictors of the total body fat. However, a valid empirical selection of the locations of a small number of skinfolds out of an infinite number of possible points still remains to be carried out. In addition to fulfilling such a requirement as. accessibility, the points at which the skinfolds are to be measured must have a definite location, facilitating repeatability of the measurements. The selected measurements should correlate highly with the total body fat, while having relatively low correlations with each other. 


\section{Intercorrelation between the criteria of fatness-leanness}

Batkin (x915) pointed out that the thickness of the subcutaneous layer varies at different parts of the body surface but added that, normally, there is a certain parallelism in the values obtained in different locations. This statement was not documented. Franzen (1929) obtained correlation coefficients varying from 0.81 to 0.85 for skinfolds measured over the biceps and the triceps of children 10-12 years of age. Reynolds (1945) noted, on the basis of roentgenograms for eight areas of the body, a fairly high association between the thickness of the subcutaneous tissues in different areas, but did not give actual correlation data.

In the younger Minnesota men the correlations of the skinfolds with each other, measured at the five points, varied from +0.752 to +0.938 . The corresponding intercorrelations for the older men were generally lower, with a range from +0.542 to +0.799 .

\section{Interindividual differences}

The amount of body fat exhibits larger differences between normal individuals than perhaps any other body constituent. In fifty guinea-pigs examined by Rathbun \& Pace (1945) the fat content varied from $\mathrm{x} \cdot 5$ to $35.8 \%$ of the body-weight. The specific gravity of the eviscerated body ranged from 1.096 to $\mathrm{r} \cdot 02 \mathrm{r}$. The range is almost as large as was reported by Moulton (1920) for beef steers maintained in a good state of nutrition until the animals were I I months old and subsequently fed at different caloric levels. The carcass of the control animal contained $18.5 \%$ fat, whereas a fattened steer had nearly twice as much $(32.6 \%)$. In an animal that lost $0.5 \mathrm{lb}$. daily for 10 months and became emaciated the fat content was only $1 \cdot 9 \%$.

In the present study the 'storage' fat, estimated from the specific gravity, varied in the younger men from o to $32.7 \%$ of the body-weight, in older men from 1.4 to $34 \cdot 2 \%$; the other fatness criteria also exhibited large individual differences. Part of these differences may be explained as 'error' of measurement, including such items as the failure to measure residual air in each individual, but the major variation is undoubtedly simply interindividual difference.

\section{SUMMARY}

I. Several criteria of leanness-fatness were used in the characterization of a representative sample of $\mathrm{I} 33$ college men (mean age $=20 \cdot 3$ years, S.D. $=x \cdot 9$ ) and $\mathrm{I} 22$ business and professional men (mean age $=49^{\circ} \circ$ years, S.D. $=2 \cdot 8$ ). Clinically, all men were free of disease.

2. Frequency distribution for relative body-weight, specific gravity, thickness of skinfolds, and the difference between the circumference of the chest and the abdomen were analysed in order to obtain norms of relative fatness.

3. Equations for prediction of specific gravity (and the corresponding percentage of body fat) from single and combined criteria of fatness were developed.

4. Implications of the data for nutritional research are considered, and the urgent need for extension of the studies to other groups is pointed out. 
The present communication is a part of a long-range study on the effects of ageing, with emphasis on the cardiovascular system. The work is being supported, in part, by funds provided by the U.S. Public Health Service. We wish to express our appreciation to $\mathrm{Mr}$ Kenneth $\mathrm{F}$. Tiede for careful statistical computations.

\section{REFERENCES}

Association of Life Insurance Medical Directors and the Actuarial Society of America (1912). MedicoActuarial Mortality Investigation, Vol. 1. New York: The Association of Life Insurance Medical Directors and The Actuarial Society of America.

Batkin, S. (1915). Yb. Kinderheilk. 82, 103.

Behnke, A. R. (1941-2). Harvey Lect. 37, 198.

Behnke, A. R. Jr., Feen, B. G. \& Welham, W. C. (1942). F. Amer. med. Ass. r18, 495.

Brožek, J. (1946). Fed. Proc. 5, I3.

Brožek, J., Carlson, W. \& Keys, A. (195I). (To be published.)

Brožek, J., Henschel, A. \& Keys, A. (1949). F. appl. Physiol. 2, 240.

Brožek, J. \& Keys, A. (I950a). Nutr. Abstr. Rev. 20, 247.

Brožek, J. \& Keys, A. (1950b). Science, 112, 788.

Davenport, C. B. (1923). Publ. Carneg. Instn, no. 329.

Edwards, T. I., McGill, K. H. \& Rowntree, L. G. (1943). Med. statist. Bull. Selective Service System, Wash., no. 2.

Food and Agriculture Organization of the United Nations (1950). Nutritional Studies, no. 5. Washington, D.C.: Food and Agriculture Organization of the United Nations.

Franzen, R. (1929). Physical Measures of Growth and Nutrition. New York: American Child Health Association.

Johnson, P. O. (1949). Statistical Methods in Research. New York: Prentice-Hall.

Keys, A., Brožek, J., Henschel, A., Mickelsen, O. \& Taylor, H. L. (1950). The Biology of Human Starvation. Minneapolis: University of Minnesota Press.

McLester, J. S. (1943). Nutrition and Diet in Health and Disease, 4th ed. Philadelphia and Isondon: W. B. Saunders.

Mitchell, H. H., Hamilton, T. S., Steggerda, F. R. \& Bean, H. W. (1945). Y. biol. Chem. $158,625$.

Moulton, C. R. (1920). F. biol. Chem. 43, 67.

Rathbun, E. N. \& Pace, N. (1945). F. biol. Chem. $15^{8}, 667$.

Reynolds, E. L. (1945). Amer. F. Phys. Anthrop. (N.S.) 3, 222.

Rony, H. R. (1940). Obesity and Leanness. Philadelphia: Lea and Febiger.

Rynearson, E. H. \& Gastineau, C. F. (1949). Obesity. Springfield, Illinois: Thomas.

Sarkisian, S. S. (1946). Nav. med. Bull., Wash., 46, 1207.

Welham, W. C. \& Behnke, A. R. Jr. (1942). F. Amer. med. Ass. r18, 498. 